\title{
Spectroscopic scale protection factor (SSPF) of solar ultraviolet radiation molecular screens. II. Substituent effect on salicylideneaniline
}

\author{
Raúl G.E. Morales *, Alexis Hidrobo and Gregorio P. Jara \\ Laboratory of Luminescence and Molecular Structure, Department of Chemistry and Center for \\ Environmental Chemistry, Faculty of Sciences, University of Chile, casilla 653, Santiago, Chile
}

Received 9 February 2000

Accepted 22 February 2000

\begin{abstract}
Salicylideneanilines present a broad absorption band and a high molar absorption coefficient in the UV-A and UV-B regions. In addition, they are photostable compounds to the solar radiation exposition. Therefore, we have recently established their potential use as a solar ultraviolet radiation molecular screens.

In the present work we have determined the dependence of the Spectroscopic Scale Protection Factor (SSPF) values with the substituent effect on the aniline ring of the salicylidene, when the substituent is an electron-acceptor group (- $\mathrm{CN},-\mathrm{COCH}_{3}$, $\left.-\mathrm{NO}_{2}\right)$ and we have compared this effect with and without an electron-donor group $\left(-\mathrm{OCH}_{3}\right)$ at para position in the salicylidene ring.

In order to determine and compare these SSPF values versus the usual Sun Protection Factor (SPF) values, a relative scale of biological nature, we have determined the electronic absorption spectra of these substituted salicylideneaniline compounds, and we have compared these spectroscopic data with homosalate, as an SPF standard compound. Our results are conclusive respect to determine the salicylideneanilines as a new family of molecular species highly efficient in the molecular screen role.
\end{abstract}

Keywords: Salicylideneanilines, SSPF, molecular screens, UV-A and UV-B spectral bands, solar action spectra

\section{Introduction}

Global depletion of the stratospheric ozone levels will continue for long time in the present century [13]. On the other hand, it is a well known fact, that the solar photochemical damage on the organic material are caused predominantly by the ultraviolet region of the electromagnetic spectrum, particularly by the UV-A $(320 \mathrm{~nm} \leqslant \lambda \leqslant 400 \mathrm{~nm})$ and UV-B $(295 \mathrm{~nm} \leqslant \lambda \leqslant 320 \mathrm{~nm})$ regions. Therefore, the photochemical damage of different organic materials at industrial scale, are being considered a source of new research in the interest to reduce these new solar problems at the earth's surface, due to an overexposure to the sun.

For long time, a complex quantitative method for determining a photochemical protection in skin by means of molecular screens have been used. This method define a sun protection factor (SPF) concept

\footnotetext{
${ }^{*}$ Corresponding author. E-mail: raulgem@abello.dic.uchile.cl.
} 
for skin only, through the UV energy required to produce a minimal erythemal (sunburn) dose (MED) on protected skin divided by the UV energy required to produce a MED on unprotected skin [4]:

$\mathrm{SPF}=\mathrm{MED}_{\text {protected }} / \mathrm{MED}_{\text {unprotected }}$.

The dose can be measured in intensity of light or in length of exposure, being the last parameter the more common method of SPF determination. However, due to the SPF method need a standard compound as reference, the Food and Drug Administration in the USA has defined the homosalate (homomenthyl salicylate) as a standard compound, where an emulsion with a given formula containing $8 \%$ of this compound dissolved in mineral oil has an SPF value of 4.24 [5].

Since this biological method, based on the skin exposure to the UV radiation, depend on several factors such as the skin type, the solar intensity variations skin response, the air and humidity conditions, etc., their usefulness is limited and only can be considered as a complex method for qualitative analysis, without extension to molecular systems of industrial application.

Therefore, in order to develop an absolute scale of protection factor values, we have recently introduced a new method based on the Spectroscopic Scale Protection Factor (SSPF) concept [6]. The SSPF is based on the solar spectral action of these molecular species, obtained under $20^{\circ}$ zenith angle of the sun actinic flux spectra at the earth' surface. Thus, the action spectra is defined by means of the integrated area of the product function between the spectroscopic absorption band and the solar spectrum, in the UV-solar region (IAS).

In the present work, we report the Spectroscopic Scale Protection Factor (SSPF) values of a series of photostable salicylideneaniline compounds [7], previously synthesized in our laboratory, and we analyze the substituent effect on the salicylideneaniline compound. Thus, our salicylideneaniline series is constituted by two kind of substituents, electron-acceptor and electron-donor groups. The electron-acceptor group is positioned on the aniline ring of the salicylidene with substituents of the type: $-\mathrm{CN},-\mathrm{COCH}_{3}$, $-\mathrm{NO}_{2}$; and we have compared the effect of these substituents when we positioned an electron-donor group $\left(-\mathrm{OCH}_{3}\right)$ at para position in the salicylidene ring.

In spite of these compounds are irritants, and they can not be used as topical compounds, their use is attractive in polymeric films or UV-transparent solid polymeric matrix [6].

\section{Materials and methods}

Salicylideneanilines (Fig. 1) were synthesized by a Schiff's bases condensation procedure stirring equimolar quantities of salicylaldehydes and the aniline in methanol solution [8]. The synthesized compounds are: salicylideneaniline (Anil-H), salicylidene- $p$-cianoaniline (Anil-CN), $p$-methoxysalicylidene-p-ciano-aniline (MeO-Anil-CN), salicylidene- $p$-acetoaniline (Anil-COMe), $p$-methoxysalicylidene- $p$-aceto-aniline (MeO-Anil-COMe), salicylidene- $p$-nitroaniline $\left(\mathrm{Anil}-\mathrm{NO}_{2}\right)$, and $p$-methoxysalicylidene-p-nitro-aniline (MeO-Anil- $\mathrm{NO}_{2}$ ). Reactives and solvents were purchased in Aldrich Chemical Co. Every one compounds under study were structurally characterized by infrared and ${ }^{1} \mathrm{H}-\mathrm{NMR}$ spectroscopy and physical properties were previously confirmed. Twice recrystallizations were done in methanol at low temperature and the compounds were purified by sublimation. The absorption spectra of fresh solutions in ethanol were prepared for spectral registration in a Perkin Elmer Lambda $11 \mathrm{UV} / \mathrm{Vis}$ at $20^{\circ} \mathrm{C}$ in quartz cells. 
<smiles>[2H]c1ccc(/C=N/c2ccc([Tl])cc2)c(O)c1</smiles>

Salicylideneaniline<smiles>CC1CC(OC(=O)c2ccccc2O)CC(C)(C)C1</smiles>

Homosalate

Fig. 1. Salicylideneaniline compounds.

\section{Results and discussion}

The spectral absorption bands of the salicylideneaniline compounds and homosalate are showed in Fig. 2. The spectral band maxima and molar absorption coefficients are presented in Table 1.

The SSPF values were determined from the integral of the action spectra ( IAS $\left._{\text {compound }}\right)$ according to:

$$
\mathrm{IAS}_{\text {compound }}=\int_{\lambda} A(\lambda) f_{0}(\lambda) \mathrm{d} \lambda
$$

where $A(\lambda)$ is the spectral absorption band of the molecular screen, $f_{0}(\lambda)$ is the actinic UV-solar flux at $20^{\circ}$ zenith angle of the earth surface (Io) determined by Demerjian et al. [9], and the integration spectral range is 295 to $400 \mathrm{~nm}$. The polynomial coefficients of the $f_{0}(\lambda)$ function to be used in Eq. (1) were determined by Morales et al. [6] (see Table 2).

Contrarily to the SPF method, where it is necessary to consider homosalate as a particular standard compound [5] with a different optical behavior in both UV-A and UV-B regions (see Fig. 2), the SSPF scale permits to compare molecular screens in terms of their absolute optical properties in both spectral ranges [6]. Therefore, partial spectral range scales such as SSPF(UV-A) and SSPF(UV-B), can be determined after Morales et al. [6], according to the following equations:

$$
\operatorname{SSPF}(\mathrm{UV}-\mathrm{A})=\int_{\mathrm{UV}-\mathrm{A}} A(\lambda) f_{0}(\lambda) \mathrm{d} \lambda, \quad 320 \mathrm{~nm} \leqslant \lambda \leqslant 400 \mathrm{~nm}
$$

and

$$
\operatorname{SSPF}(\mathrm{UV}-\mathrm{B})=\int_{\mathrm{UV}-\mathrm{B}} A(\lambda) f_{0}(\lambda) \mathrm{d} \lambda, \quad 297.5 \mathrm{~nm} \leqslant \lambda \leqslant 320 \mathrm{~nm} .
$$




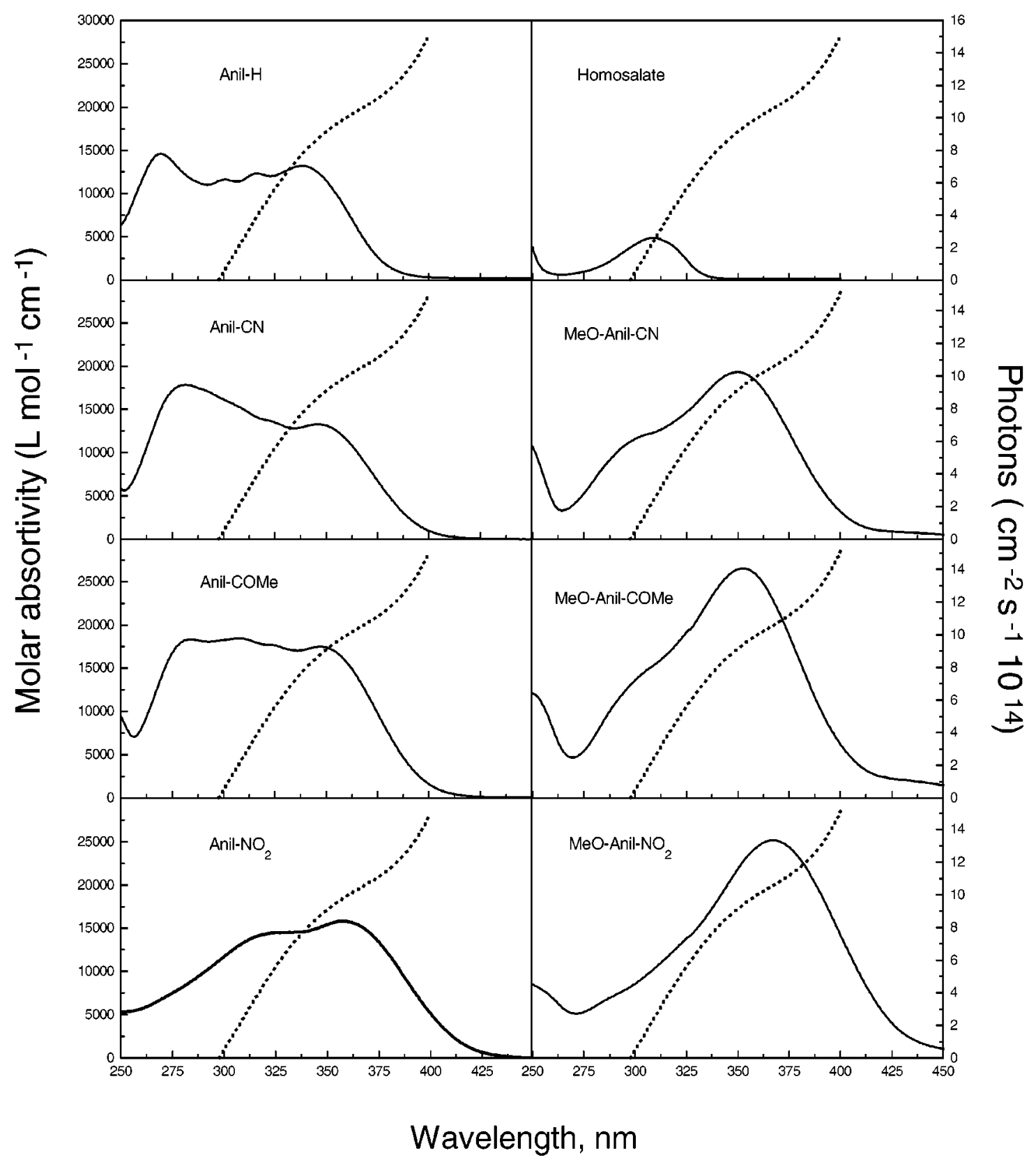

Fig. 2. Spectral absorption bands of salicylideneanilines, homosalate and the actinic flux at the earth's surface at $20^{\circ}$ zenith angle.

In Table 1 we show the corresponding calculated SSPF, SSPF(UV-A) and SSPF(UV-B) for every compound under study, including the homosalate compound. On the other hand, the Sun Protection Factor (SPF) of the salicylideneaniline series have been determined relative to homosalate (SPF $=4.24$ ) by means of the following equation:

$$
\mathrm{SPF}_{\text {compound }}=4.24\left(\mathrm{IAS}_{\text {compound }}\right) / \mathrm{IAS}_{\text {homosalate }} \text {, }
$$


Table 1

Spectral absorption band maxima, molar absorption coefficient, SSPF (photons $\cdot \mathrm{nm} \cdot \mathrm{mole}^{-1} \cdot \mathrm{s}^{-1}$ ) and SPF of the salicylideneanilines in the UV-A, UV-B and (UV-A + UV-B) regions

\begin{tabular}{lccllcc}
\hline Compounds & $\lambda_{\max }(\mathrm{nm})$ & $\begin{array}{c}\varepsilon \times 10^{4} \\
(1 / \mathrm{mol} \mathrm{cm})\end{array}$ & $\begin{array}{c}\text { SSPF } \\
(\mathrm{UV}-\mathrm{A})\end{array}$ & $\begin{array}{c}\text { SSPF } \\
(\mathrm{UV}-\mathrm{B})\end{array}$ & $\begin{array}{c}\text { SSPF } \\
(\mathrm{UV}-\mathrm{A}+\mathrm{UV}-\mathrm{B})\end{array}$ & SPF \\
\hline Anil-H & & 1.32 & 0.792 & 0.107 & 0.899 & 57.0 \\
Anil-CN & 338 & 1.33 & 1.08 & 0.13 & 1.21 & 76.8 \\
Anil-COMe & 346 & 1.75 & 1.48 & 0.16 & 1.64 & 104 \\
Anil-NO $_{2}$ & 347 & 1.58 & 1.65 & 0.12 & 1.77 & 112 \\
MeO-Anil-CN $^{\mathrm{a}}$ & 357 & 1.93 & 1.69 & 0.11 & 1.80 & 114 \\
$\mathrm{MeO}-A n i l-C O M e$ & 350 & 2.65 & 2.44 & 0.14 & 2.58 & 164 \\
MeO-Anil-NO $_{2}$ & 368 & 2.52 & 2.69 & 0.10 & 2.79 & 177 \\
Homosalate $^{\mathrm{a}, \mathrm{b}}$ & 309 & 0.485 & 0.0277 & 0.0391 & 0.0668 & 4.24 \\
\hline
\end{tabular}

${ }^{\mathrm{a}} \mathrm{See}[6] .{ }^{\mathrm{b}}$ Formulation in mineral oil and dissolved in ethanol.

Table 2

Morales and Jara polynomial function ${ }^{\mathrm{a}}$ of the UVsolar actinic flux at the earth's surface at $20^{\circ}$ zenith angle, $f_{0}(\lambda)=a_{4} \lambda^{4}+a_{3} \lambda^{3}+a_{2} \lambda^{2}+a_{1} \lambda+a_{0}$

\begin{tabular}{ccl}
\hline Parameters & Value & \multicolumn{1}{c}{ SD } \\
\hline$a_{0}$ & $4.2340923 \mathrm{E}+3$ & $5.0139877 \mathrm{E}+2$ \\
$a_{1}$ & $-5.1846146 \mathrm{E}+1$ & 5.78352 \\
$a_{2}$ & $2.3520611 \mathrm{E}-1$ & $2.494 \mathrm{E}-2$ \\
$a_{3}$ & $-4.693092 \mathrm{E}-4$ & $0.5 \mathrm{E}-4$ \\
$a_{4}$ & $3.4852772 \mathrm{E}-7$ & $3.4022 \mathrm{E}-8$ \\
\hline
\end{tabular}

${ }^{\mathrm{a}}$ See [6].

where $\mathrm{IAS}_{\text {compound }}$ and IAS $\mathrm{S}_{\text {homosalate }}$ are the integrated area of the action spectra in ethanol of the (UV-A + UV-B) region. These calculations are included in Table 1.

From the SSPF values result interesting to observe that the electron-acceptor as well as the electrondonor substituent effect determine an increase of the solar protection factor respect to salicylideneaniline. Particularly, the main effects is observed in the UV-A region, while the UV-B region is practically constant (see Table 1). However, from a comparative point of view, the effect of the electron donor group, i.e., the methoxy group, on the SSPF values induce a small diminution in the UV-B range, but a significant augmentation on the UV-A range. Thus, the net substituent effect on the salicylideneaniline structure permits to determine a relative order of SSPF values according to:

$$
\begin{aligned}
\text { Anil-H }<\text { Anil-CN }<\text { Anil-COMe } & <\text { Anil- } \mathrm{NO}_{2}<\text { MeO-Anil-CN }<\text { MeO-Anil-COMe } \\
& <\text { MeO-Anil- } \mathrm{NO}_{2} .
\end{aligned}
$$

Finally, all these species present a SSPF bigger than homosalate, being Anil-H the minor with 13.5 times bigger than homosalate and $\mathrm{MeO}-\mathrm{Anil}-\mathrm{NO}_{2}$ the major, with 42 times bigger than the same standard.

If we consider the high photostability of these species to the UV-solar radiation as well as the high SSPF values determined through this work, our results permit us to establish these salicylideneanilines as a particular case of good molecular screens. 


\section{Acknowledgments}

The authors acknowledged to the Fondo Nacional de Ciencias y Tecnología (Fondecyt) by the financial support, Grant 1970787. We extend our acknowledgments to Mr Luis Amigo by the syntheses of some salicylidenes and Mr Víctor Vargas for helpful discussions about these compounds.

\section{References}

[1] P. Crutzen, Angew. Chem. Int. Ed. Engl. 35 (1996), 758.

[2] D. Kley, Science 276 (1997), 1043.

[3] A.R. Webb, J. Photochem. Photobiol. B: Biology 31 (1995), 9.

[4] G. Pittet and S.A. Givaudan, Drug Cosmetic Ind. 143 (1988), 24.

[5] Department of Health, Education and Welfare, US, FDA, Sunscreen drug products for over-the-counter human drugs, proposed safety, effective and labeling conditions, Federal Register, 1978, 43, 38 206-38 269.

[6] R.G.E. Morales, G.P. Jara and V. Vargas, J. Photochem. Photobiol. A: Chem. 119 (1998), 143.

[7] V. Vargas, Bol. Soc. Chil. Quim. 41 (1996), 331.

[8] A.I. Vogel, Practical Organic Chemistry, Longmans, London, 1967.

[9] K.L. Demerjian, K.L. Schere and J.T. Peterson, Theoretical estimates of actinic flux and photolytic rate constants of atmospheric species in the lower troposphere, in: Advances in Environmental Science and Technology, Vol. 10, John Wiley \& Sons, Inc., 1980, p. 401. 


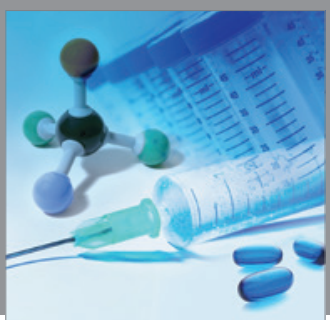

International Journal of

Medicinal Chemistry

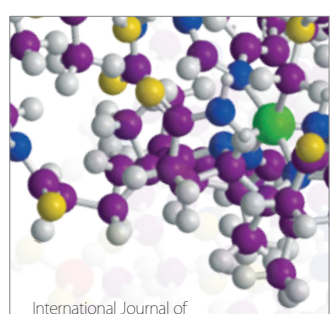

Carbohydrate Chemistry

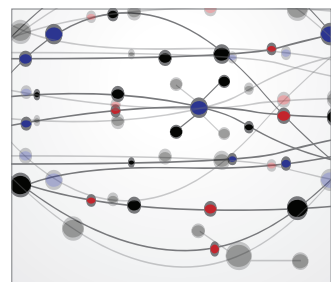

The Scientific World Journal
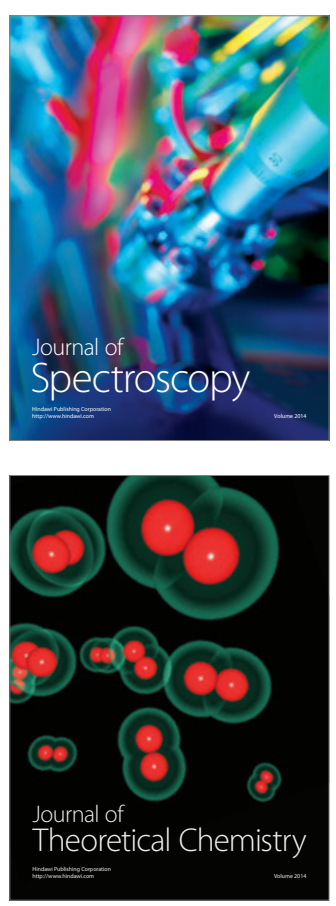
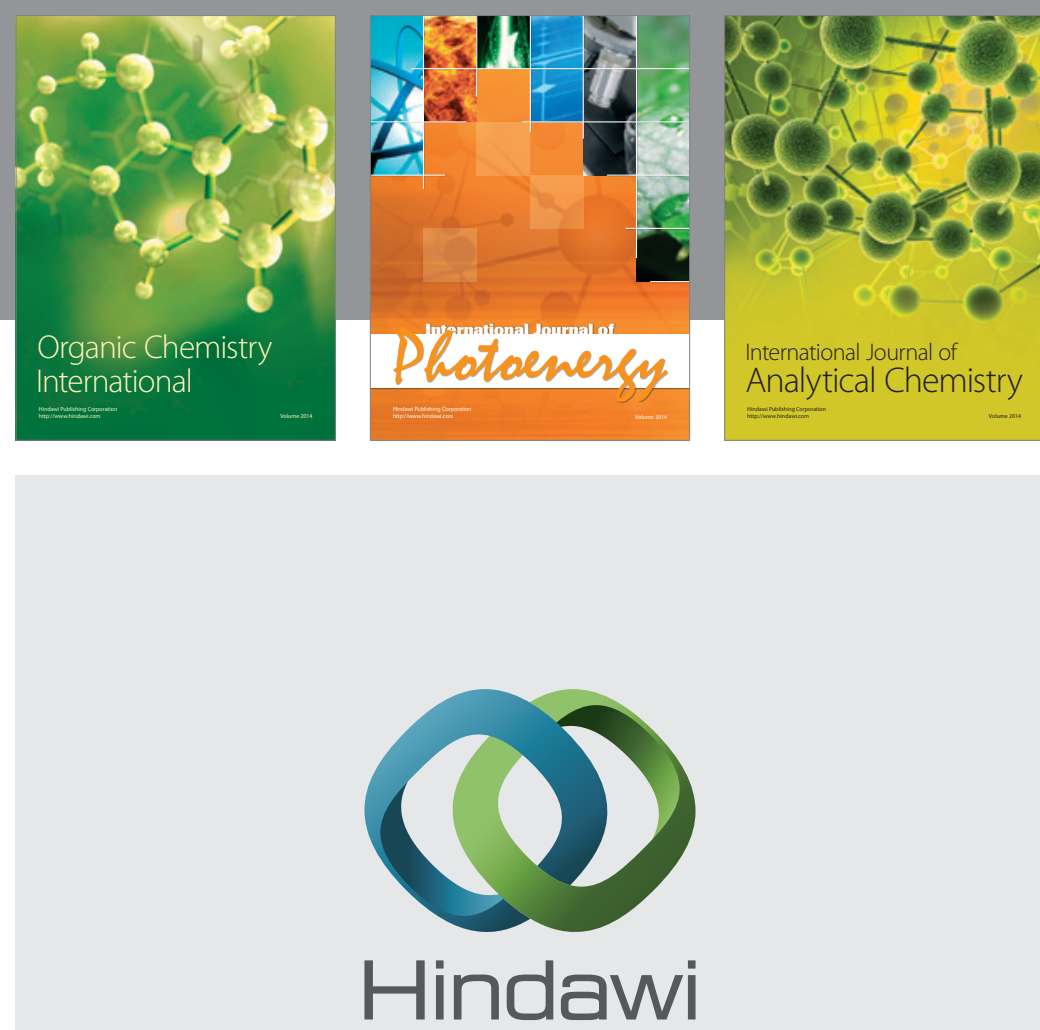

Submit your manuscripts at

http://www.hindawi.com
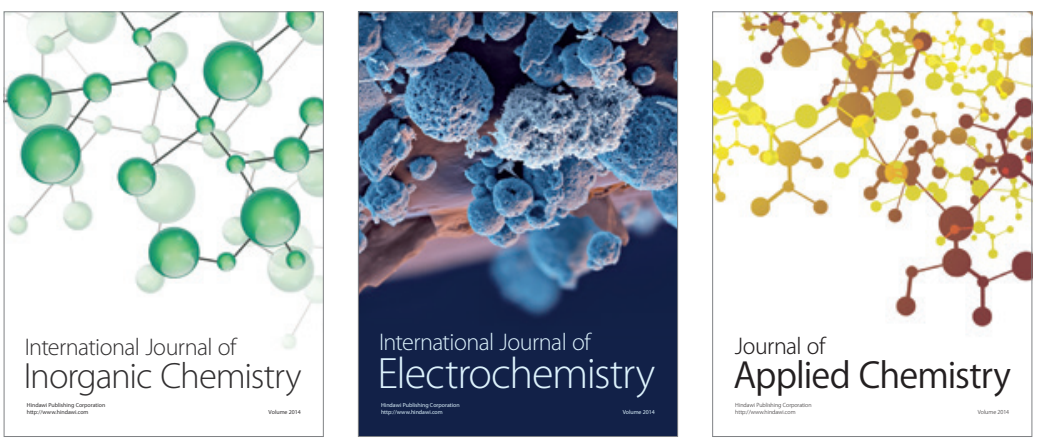

Journal of

Applied Chemistry
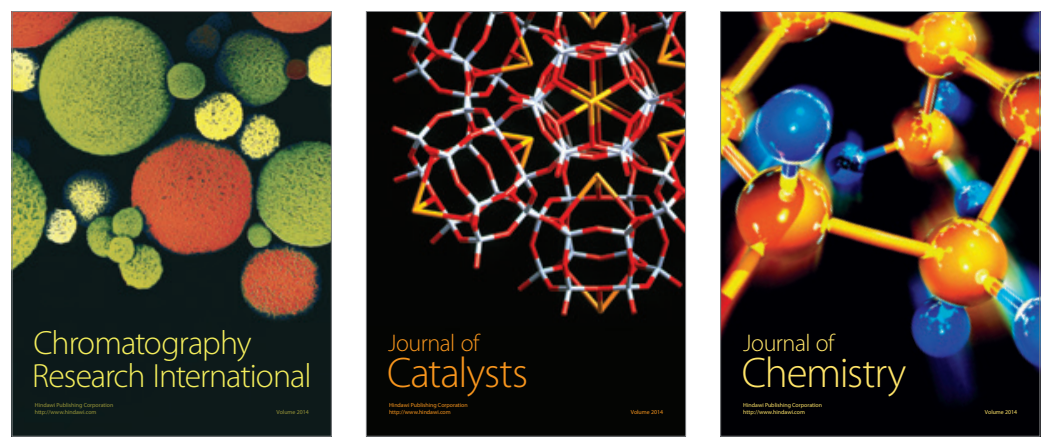
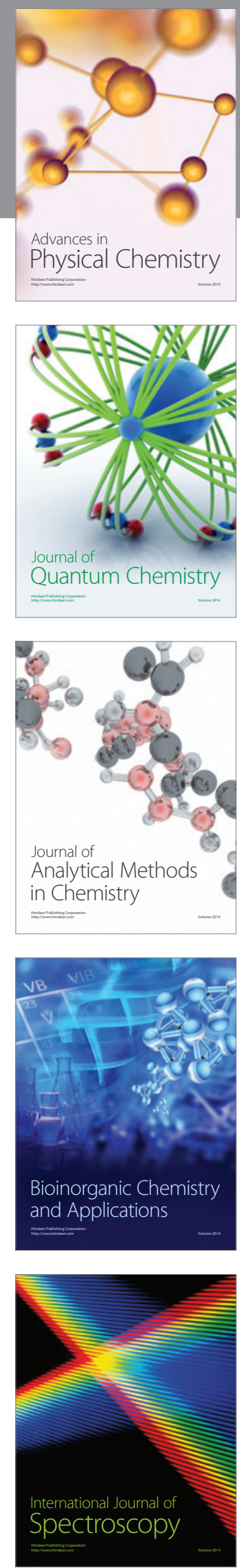